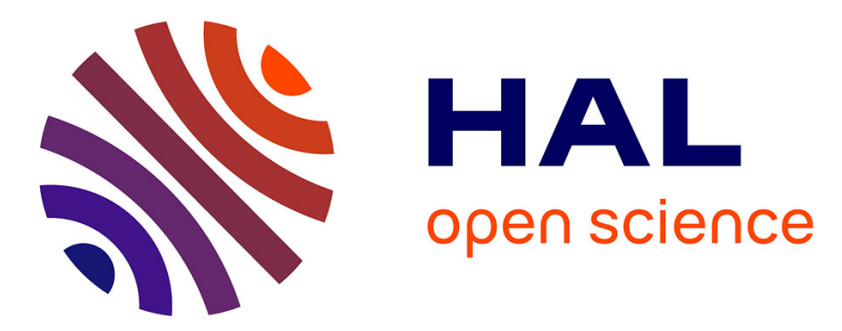

\title{
Introduction of Cyclopropyl and Cyclobutyl Ring on Alkyl Iodides through Cobalt-Catalyzed Cross-Coupling
} Claire Andersen, Vincent Ferey, Marc Daumas, Patrick Bernardelli, Amandine Guérinot, Janine Cossy

\section{- To cite this version:}

Claire Andersen, Vincent Ferey, Marc Daumas, Patrick Bernardelli, Amandine Guérinot, et al.. Introduction of Cyclopropyl and Cyclobutyl Ring on Alkyl Iodides through Cobalt-Catalyzed CrossCoupling. Organic Letters, 2019, 21 (7), pp.2285-2289. 10.1021/acs.orglett.9b00579 . hal-02533172

HAL Id: hal-02533172

https://hal.science/hal-02533172

Submitted on 20 May 2021

HAL is a multi-disciplinary open access archive for the deposit and dissemination of scientific research documents, whether they are published or not. The documents may come from teaching and research institutions in France or abroad, or from public or private research centers.
L'archive ouverte pluridisciplinaire HAL, est destinée au dépôt et à la diffusion de documents scientifiques de niveau recherche, publiés ou non, émanant des établissements d'enseignement et de recherche français ou étrangers, des laboratoires publics ou privés. 


\title{
Introduction of cyclopropyl and cyclobutyl ring on alkyl io- dides through cobalt-catalyzed cross-coupling
}

\author{
Claire Andersen, ${ }^{[\mathrm{a}]}$ Vincent Ferey, ${ }^{[\mathrm{b}]}$ Marc Daumas, ${ }^{[\mathrm{c}]}$ Patrick Bernardelli, ${ }^{[\mathrm{d}]}$ Amandine Guérinot, ${ }^{*}{ }^{[\mathrm{a}]}$ Janine Cos- \\ $\mathrm{sy}^{*[\mathrm{a}]}$
}

[a] Molecular, Macromolecular Chemistry and Materials, ESPCI Paris, CNRS, PSL University, 10 rue Vauquelin, 75005 Paris, France. [b] Sanofi R\&D, 371 rue du professeur Joseph Blayac, 34080 Montpellier, France. [c] Sanofi Chimie, Route d'Avignon, 30390 Aramon, France. [d] Sanofi R\&D, 1 avenue Pierre Brossolette, 91380 Chilly-Mazarin, France.

Supporting Information Placeholder

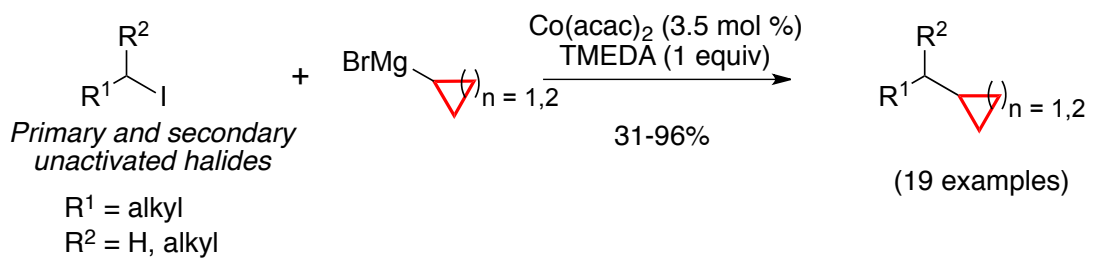

\begin{abstract}
A cobalt-catalyzed cross-coupling between alkyl iodides and cyclopropyl, cyclobutyl and alkenyl Grignard reagents is disclosed. The reaction allows the introduction of strained rings on a large panel of primary and secondary alkyl iodides. The catalytic system is simple, non-expensive and the reaction is general, chemoselective and diastereoconvergent. The alkene resulting from the cross-coupling can be transformed to substituted cyclopropanes using a Simmons-Smith reaction. The formation of radical intermediates during the coupling is hypothesized.
\end{abstract}

Since the isolation of (+)-trans-chrysanthemic acid, ${ }^{1}$ a myriad of cyclopropane-containing natural products has been extracted from diverse sources such as fungi, plants, marine organisms or microorganisms. ${ }^{2}$ The rigidity of the cycle, its ring strain associated to its three dimensionality notably raised the attention of medicinal chemists and, since the 1960s, cyclopropanes have been introduced in a wide variety of pharmaceutically active compounds. ${ }^{3,4}$ Particularly, the identification of cyclopropanes as excellent surrogates of phenyl ring in bioactive molecules was an important breakthrough in drug design. ${ }^{5,6}$ Cyclobutanes are less popular than cyclopropanes but their presence in bioactive natural products ${ }^{7}$ as well as the need for an exploration of the chemical space in drug design motivate an increasing interest for this cycle. Thus, a large diversity of methods including ring-closure reactions, rearrangements, pericyclic reactions and carbenoid reactions has been developed to access either cyclopropanes or cyclobutanes. ${ }^{3,7,8}$ All these reactions involve the formation of the ring but the direct introduction of a pre-existing carbocycle is an alternative attractive strategy. With this idea in mind, metal-catalyzed cross-coupling reactions between a halide and an organometallic reagent featuring the strained cycle have been considered. ${ }^{9,10}$ Alkyl halides are often considered as challenging partners in cross-coupling reactions due to $\beta$-elimination or dehalogenation side-reactions. As a result, most of the existing Kumada, ${ }^{11}$ Suzuki $^{12}$ or Negishi ${ }^{13}$ coupling between cyclopropyl/cyclobutyl organometallics and alkyl halides are limited to activated allylic or benzylic halides (Scheme 1, eq. 1). To date, only copper- and iron-catalyzed cross-couplings allowed the introduction of cyclopropyl/cyclobutyl rings on unactivated alkyl halides albeit with a restriction to primary alkyl halides (Scheme 1, eq. 2)..$^{14,15,16}$ To the best of our knowledge, a single example of cyclopropanation of a secondary unactivated alkyl chloride has been reported using a Ni-catalyzed Suzuki-type cross-coupling (Scheme 1 , eq. 3). ${ }^{17}$

Scheme 1. Introduction of cyclopropyl and cyclobutyl rings through metal-catalyzed cross-coupling.

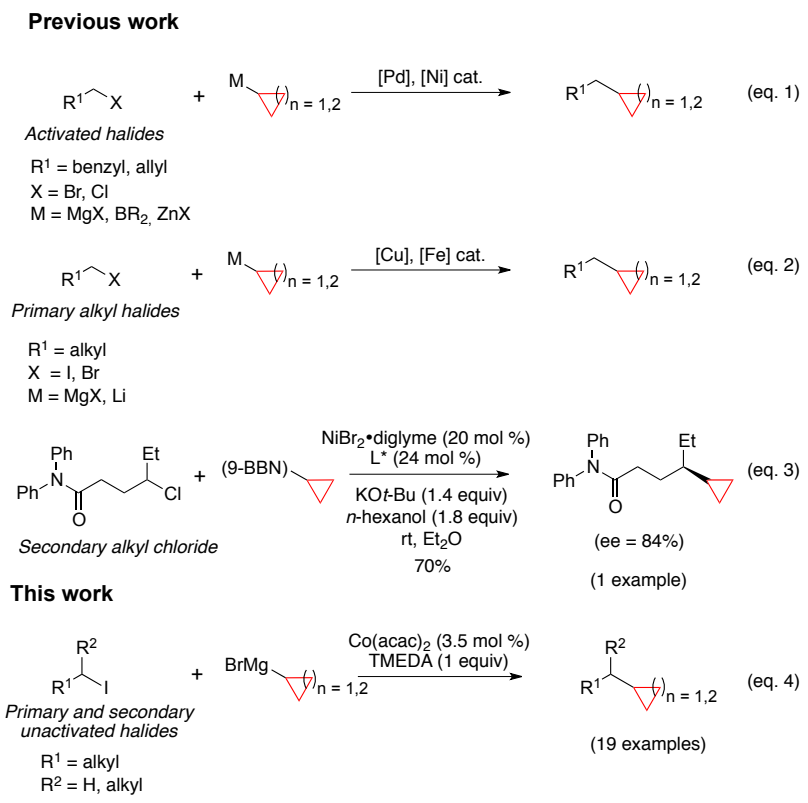


Over the past decades, cobalt-catalyzed cross-coupling has emerged as a powerful tool, especially enabling the extensive use of alkyl halides as partners. ${ }^{18,19}$ In the course of our studies towards the development of sustainable cross-coupling reactions, ${ }^{20}$ the cobaltcatalyzed alkylation of cyclopropyl- and cyclobutylmagnesium bromides with alkyl halides was developed. The method allows the facile and direct introduction of the strained carbocycles on a variety of primary and secondary alkyl halides including molecules featuring attractive scaffolds such as $N$-heterocycles. It was extended to alkenyl Grignard reagents as the resulting alkenes could be further transformed to cyclopropanes (Scheme 1, eq. 4).

The reaction between the primary alkyl iodide $\mathbf{1 . 1}$ and cyclopropylmagnesium bromide was first examined. Investigations were conducted to identify the best conditions for the cross-coupling and a range of ligands, catalysts, temperature, solvents and addition speed and were screened. Only the key facts of this optimization study are reported below. ${ }^{21}$ Besides the desired cross-coupling product 2.1, several by-products could be formed during the reaction such as the terminal alkene $\mathbf{3 . 1}$ resulting from an elimination, the internal alkene $\mathbf{4 . 1}$ obtained after the double bond migration of 3.1 or the dehalogenated product 5.1.22 Based on our experience, we first selected $\mathrm{CoCl}_{2}(10 \mathrm{~mol} \%)$ as a catalyst associated to a diamine ligand $(20 \mathrm{~mol} \%)$. With $(R, R)$ tetramethylcyclohexanediamine (TMCD), the coupling product was obtained in a moderate yield of $42 \%$ due to an important simultaneous formation of side-products $\mathbf{4 . 1}$ and $\mathbf{5 . 1}$ (Table 1, entry 1). Using tetramethylethylenediamine (TMEDA) slightly improved the selectivity of the reaction toward the formation of $\mathbf{2 . 1}$ (Table 1, entry 2). Phosphine ligands were tested delivering traces or small amount of 2.1, the best results being obtained with triphenylphosphine (Table 1, entry 3). TMEDA was thus selected and a decrease of the temperature was envisioned to improve the selectivity. Indeed, working at $0{ }^{\circ} \mathrm{C}$ contributed to reduce the alkenes formation, furnishing $\mathbf{2 . 1}$ in 69\% yield (Table 1, entry 4). However, reducing the temperature at $-25{ }^{\circ} \mathrm{C}$ did not allow to suppress the elimination and affected the conversion of the iodide (Table 1, entry 5). The addition rate of the Grignard reagent was identified as a significant parameter and using a syringe pump $(\mathrm{v}=$ $\left.0.52 \mathrm{mmol} . \mathrm{h}^{-1}\right)$ proved beneficial to the selectivity and reproducibility of the reaction (Table 1, entry 6). Pleasingly, the catalytic loading could be reduced to $3.5 \mathrm{~mol} \%$ for both the cobalt salt and TMEDA (Table 1, entry 7) and when $\mathrm{CoCl}_{2}$ was changed for the non-hygroscopic $\mathrm{Co}(\mathrm{acac})_{2}$, the coupling product was obtained with a good yield of $80 \%$ (Table 1 , entry 8 ). However, during the course of our studies, the introduction of 1 equiv of TMEDA appeared crucial to ensure the generality of the reaction and, under these conditions, iodide $\mathbf{1 . 1}$ was efficiently transformed to $\mathbf{2 . 1}$ (84\%) (Table 1, entry 9). ${ }^{23,24}$
Table 1. Optimization of the reaction conditions.

\begin{tabular}{|c|c|c|c|c|c|c|}
\hline $\begin{array}{l}\mathrm{MeO} \\
=\end{array}$ & 1.1 & $\Delta \frac{\stackrel{[\mathrm{Co}]}{\mathrm{L}(\mathrm{y}}}{\mathrm{T},}$ & $\begin{array}{l}\frac{\%)}{\%)} \\
\frac{\%)}{H F} \\
+ \\
+\end{array}$ & $\mathrm{Ar} \underset{4.1}{2.1}$ & $+\mathrm{Ar} \widehat{3.1}$ & \\
\hline entry & $\begin{array}{l}{[\mathrm{Co}]} \\
(\mathrm{mol} \%)\end{array}$ & $\begin{array}{l}\mathrm{L} \\
(\mathrm{mol} \%)\end{array}$ & $\mathrm{T}^{\circ} \mathrm{C}$ & $\begin{array}{l}\mathbf{2 . 1}^{[\mathrm{a}]} \\
(\%)\end{array}$ & $\begin{array}{l}3.1 \\
+4.1^{[a} \\
](\%)\end{array}$ & $\begin{array}{l}\mathbf{5 . 1}^{[\mathrm{a}]} \\
(\%)\end{array}$ \\
\hline 1 & $\begin{array}{l}\mathrm{CoCl}_{2} \\
(10)\end{array}$ & $\begin{array}{l}\text { TMCD } \\
(20)\end{array}$ & $\mathrm{rt}$ & 42 & 28 & 11 \\
\hline 2 & $\begin{array}{l}\mathrm{CoCl}_{2} \\
(10)\end{array}$ & $\begin{array}{l}\text { TMEDA } \\
\text { (20) }\end{array}$ & $\mathrm{rt}$ & 56 & 17 & $<5$ \\
\hline 3 & $\begin{array}{l}\mathrm{CoCl}_{2} \\
(10)\end{array}$ & $\begin{array}{l}\mathrm{PPh}_{3} \\
(20)\end{array}$ & $\mathrm{rt}$ & 28 & 24 & 6 \\
\hline 4 & $\begin{array}{l}\mathrm{CoCl}_{2} \\
(10)\end{array}$ & $\begin{array}{l}\text { TMEDA } \\
(20)\end{array}$ & 0 & 69 & 6 & $<5$ \\
\hline $5^{[\mathrm{b}]}$ & $\begin{array}{l}\mathrm{CoCl}_{2} \\
(10)\end{array}$ & $\begin{array}{l}\text { TMEDA } \\
(20)\end{array}$ & -25 & 37 & 14 & 6 \\
\hline $6^{[c]}$ & $\begin{array}{l}\mathrm{CoCl}_{2} \\
(10)\end{array}$ & $\begin{array}{l}\text { TMEDA } \\
(20)\end{array}$ & 0 & 76 & $<5$ & $<5$ \\
\hline $7^{[c]}$ & $\begin{array}{l}\mathrm{CoCl}_{2} \\
(3.5)\end{array}$ & $\begin{array}{l}\text { TMEDA } \\
(3.5)\end{array}$ & 0 & 73 & 5 & $<5$ \\
\hline $8^{[\mathrm{c}]}$ & $\begin{array}{l}\mathrm{Co}(\mathrm{acac})_{2} \\
(3.5)\end{array}$ & $\begin{array}{l}\text { TMEDA } \\
(3.5)\end{array}$ & 0 & 80 & $<5$ & $<5$ \\
\hline $9^{[c]}$ & $\begin{array}{l}\mathrm{Co}(\mathrm{acac})_{2} \\
(3.5)\end{array}$ & $\begin{array}{l}\text { TMEDA } \\
(100)\end{array}$ & 0 & 84 & $<5$ & $<5$ \\
\hline
\end{tabular}

[a] Yields were calculated from the ${ }^{1} \mathrm{H}$ NMR spectrum of the mixture of 2-5 obtained after flash column chromatography. [b] Unreacted iodide $\mathbf{1 . 1}$ was observed (13\%). [c] Slow addition of the Grignard reagent (0.52 mmol.h$\left.{ }^{1}\right)$.

With the optimized conditions in hand, the scope of the reaction was examined and a range of primary iodides was first evaluated. ${ }^{25}$ The presence of a protected alcohol, either as a benzyl ether or as a silyl ether, on the alkyl iodide was well tolerated and the corresponding coupling products were formed in good yields ( $86 \%$ and $89 \%$ respectively). When an alkyl iodide bearing an aryl bromide was involved in the cross-coupling, a selective introduction of the cyclopropyl group on the alkyl chain was observed and $\mathbf{2 . 4}$ was obtained with a $78 \%$ yield. This chemoselectivity towards alkyl iodides allows the use of polyfunctional molecules, offering opportunities for further functionalization. When a cyano group was present on the alkyl iodide, a significant drop in yield of the coupling product was observed (31\%), mainly due to the undesired addition of the Grignard reagent on the electrophilic nitrile moiety. The steric hindrance induced by a gem-dimethyl group could suppress this side reaction allowing the coupling to proceed with high chemoselectivity $(\mathbf{2 . 6}, \mathbf{8 1} \%)$. Pleasingly, an ester group was also compatible with the reaction conditions as $\mathbf{2 . 7}$ was isolated in $56 \%$ yield with no contamination by elimination or dehalogenation side products (Scheme 2$){ }^{26}$

Scheme 2. Cross-coupling between cyclopropyl magnesium bromide and primary alkyl iodides. 


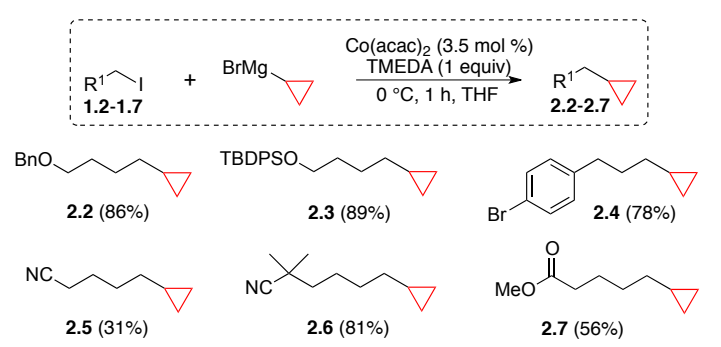

Only one example of cross-couplings between a cyclopropyl organometallic derivative and a secondary alkyl halide has been described in the literature and we thus turned our attention to these challenging substrates. A modest selectivity toward the formation of the coupling product was observed when the acyclic secondary alkyl iodide 1.8 was treated under the developed conditions, resulting in a moderate yield in $\mathbf{2 . 8} .^{27}$ Surprisingly, the formation of the elimination and dehalogenation products was considerably reduced using alkyl iodides $\mathbf{1 . 9}$ or $\mathbf{1 . 1 0}$, which incorporate a bis-protected amine group or a silyl ether. Iodo $N$-heterocycles including piperidine, pyrrolidine and azetidine were identified as excellent partners in this cross-coupling reactions with cyclopropylmagnesium bromide affording the coupling products with yields up to $96 \%$. $\mathrm{N}$-Carbamate as well as $\mathrm{N}$-tosyl protecting groups were tolerated. Pleasingly, the 2,4-disubstituted piperidine $\mathbf{2 . 1 2}$ incorporating an aromatic bromide was obtained in good yield as a single diastereomer, highlighting the chemoselectivity of the reaction. These results are valuable as these heterocycles are ubiquitous in pharmaceuticals (Scheme 3). ${ }^{25}$

Scheme 3. Cross-coupling between cyclopropyl magnesium bromide and secondary alkyl iodides.

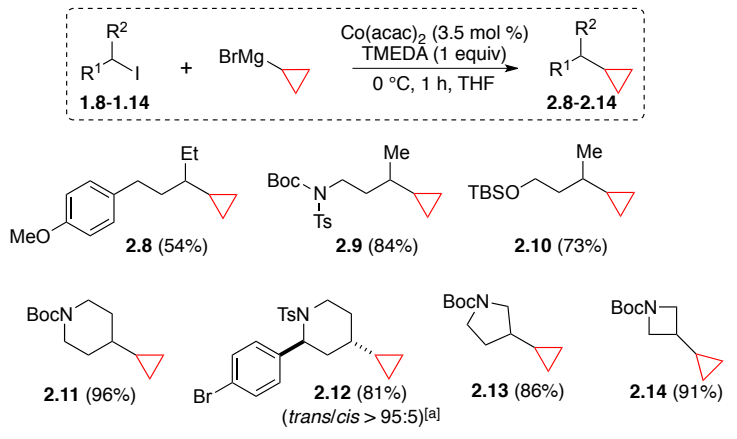

[a] Starting from the trans-iodide $(\mathrm{dr}=95: 5)$

Interestingly, when a disubstituted iodo-cyclohexane was involved in the cross-coupling, the trans-product $\mathbf{2 . 1 5}$ was exclusively obtained, whatever the diastereomeric ratio of the starting iodide (Scheme 4). The diastereoconvergence of the cross-coupling could indicate the formation of radical intermediates. ${ }^{19 \mathrm{a}, 28}$

\section{Scheme 4. Diastereoconvergence of the cross-coupling}

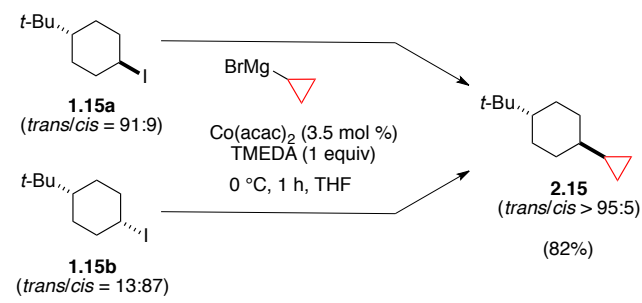

To add a clue in favor of the presence of radicals during the coupling, the radical-clock $\mathbf{1 . 1 6}$ was treated under the optimized con- ditions and bicyclic compound 2.16, resulting from a 5-exo-trig cyclization prior to the cross-coupling, was obtained as a sole product. This result suggests the existence of a single electron transfer from the active cobalt species to the alkyl iodide generating a transient radical that could add to the double bond. Recombination with the cobalt species, transmetalation and reductive elimination would then deliver the bicyclic compound featuring the cyclopropane ring (Scheme 5). ${ }^{29}$

\section{Scheme 5. Use of a radical-clock in the cross-coupling}

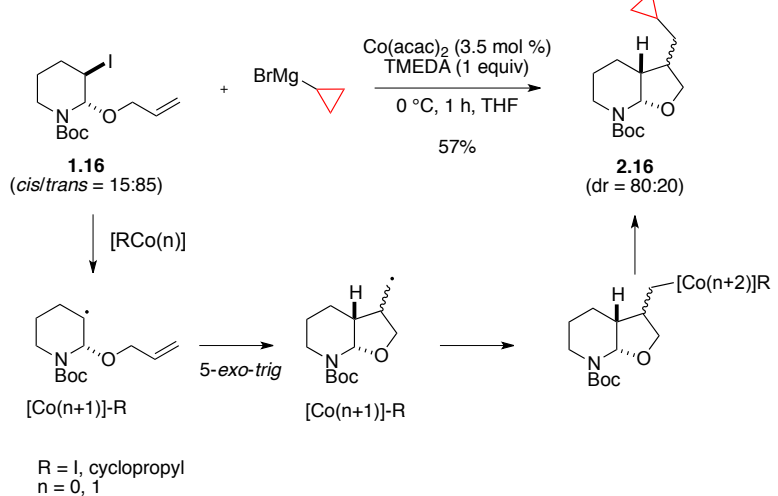

The introduction of polysubstituted cyclopropanes on alkyl iodides would require the preparation of the corresponding Grignard reagents that could necessitate laborious syntheses of halide precursors. As an alternative strategy, we envisioned to perform a cobalt-catalyzed alkenylation of the alkyl iodide followed by a cyclopropanation of the resulting olefin. ${ }^{30}$ Pleasingly, we found that similar conditions [ $\mathrm{Co}(\mathrm{acac})_{2}(3.5 \mathrm{~mol} \%)$, TMEDA (1 equiv)] were suitable for the alkenylation of both primary and secondary alkyl iodides with various alkenyl Grignard reagents (Scheme 6). ${ }^{25,31}$

\section{Scheme 6. Co-catalyzed alkenylation of alkyl iodides}

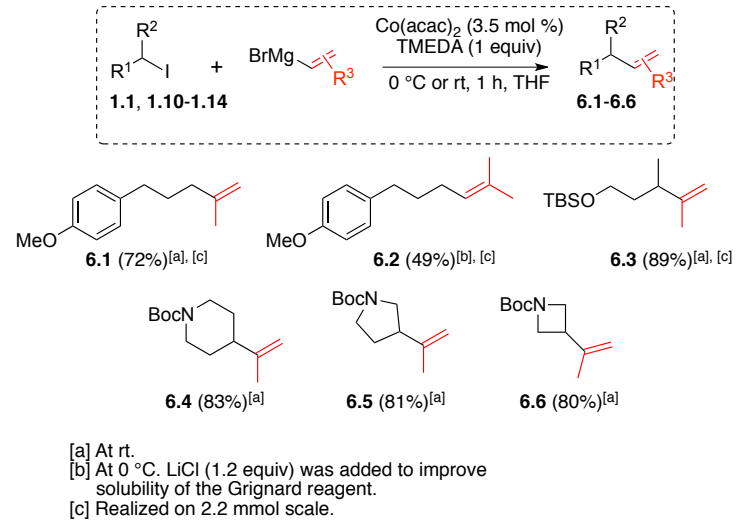

Some of the so-formed alkenes could then be involved in a Simmons-Smith type reaction to afford polysubstituted cyclopropanes (Scheme 7). 


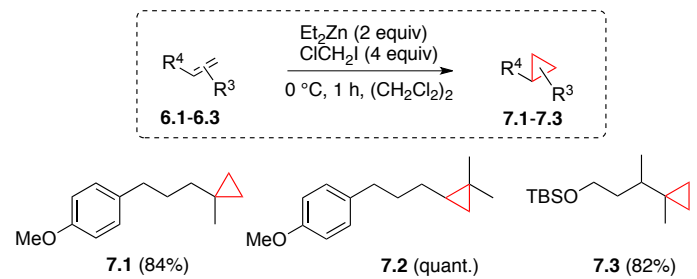

Finally, the coupling was extended to the introduction of a cyclobutane moiety on alkyl iodides. Good yields in the coupling products were obtained with primary and secondary alkyl iodides including iodo $\mathrm{N}$-heterocycles (Scheme 8). ${ }^{25}$ To the best of our knowledge, this reaction is the first example of cyclobutyl ring introduction on a secondary alkyl halide through a metal-catalyzed cross-coupling.

Scheme 8. Co-catalyzed cross-coupling between halides and cyclobutylmagnesium bromide.

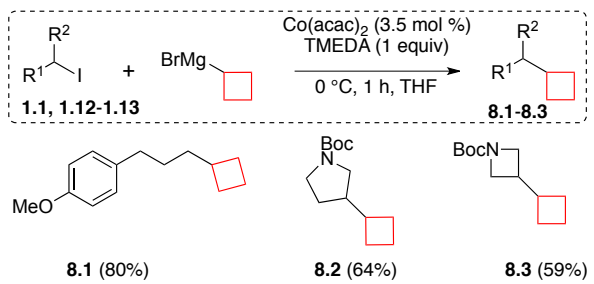

In summary, we developed a flexible, efficient and cost-effective cross-coupling allowing the introduction of cyclopropyl, cyclobutyl and alkenyl moieties on both primary and secondary alkyl iodides. The reaction tolerated an array of functional groups and was applied to the functionalization of $N$-heterocycles, which are valuable scaffolds in pharmaceutical industry. To the best of our knowledge, this is the first general cross-coupling of cyclopropyl and cyclobutyl magnesium bromides with alkyl iodides including secondary iodides. In addition, alkenyl Grignard reagents are also suitable partners resulting in the corresponding alkenes that can be transformed into polysubstituted cyclopropanes. The formation of radical intermediates could be hypothesized and could explain the diastereoconvergence of the coupling. This cross-coupling appears as a promising method for the late-stage introduction of cyclopropyl or cyclobutyl rings and could thus become an attractive tool for the design and synthesis of bioactive molecules for medicinal chemists.

\section{ASSOCIATED CONTENT}

\section{Supporting Information}

Experimental procedures and spectral data for all new compounds. The Supporting Information is available free of charge on the ACS Publications website.

\section{AUTHOR INFORMATION}

\section{Corresponding Author}

*E-mail: janine.cossy@espci.fr; amandine.guerinot@espci.fr

\section{Notes}

The authors declare no conflict of interests.

\section{ACKNOWLEDGMENT}

We thank Sanofi for financial support (C. A).

\section{REFERENCES}

${ }^{1}$ Staudinger, H.; Ruzicka, L. Helv. Chim. Acta 1924, 7, 177.

2 a) Donaldson, W. A. Tetrahedron 2001, 57, 8589. b) Wessjohann, L. A.; Brandt, W. Chem. Rev. 2003, 103, 1625. c) Tang, P.; Qin, Y. Synthesis 2012, 44, 2969. d) Chen, D. Y.-K.; Pouwer, R. H.; Richard, J.-A. Chem. Soc. Rev. 2012, 41, 4631. e) Ebner, C.; Carreira, E. M. Chem. Rev. 2017, 117, 11651.

${ }^{3}$ Selected book and reviews: a) Reissig, H.-U. in The Chemistry of the Cyclopropyl Group, (Ed.: Z. Rappoport), Wiley-VCH, 1987. b) Lebel, H.; Marcoux, J.-F.; Molinaro, C. ; Charrette, A. B. Chem. Rev. 2003, 103, 977. c) Pietruszka, J. Chem. Rev. 2003, 103, 1051. d) Ganesh, V.; Chandrasekaran, S. Synthesis 2016, 48, 4347.

4 a) Burger, A. Prog. Drug Res. 1971, 15, 227. b) Gagnon, A.; Duplessis, M.; Fader, L. Org. Prep. Proced. Int. 2010, 42, 1. c) Taylor, R. D.; MacCoss, M.; Lawson, A. D. G. J. Med. Chem. 2014, 57, 5845. d) Talele, T. T. J. Med. Chem. 2016, 59, 8712 and references therein.

${ }^{5}$ Lovering, F.; Bikker, J.; Humblet, C. J. Med. Chem. 2009, 52, 6752.

${ }^{6}$ See for example: a) Qiao, J. X.; Cheney, D. L.; Alexander, R. S.; Smallwood, A. M.; King, S. R.; He, K.; Rendina, A. R.; Luettgen, J. M.; Knabb, R M.; Wexler, R. R.; Lam, P. Y. S. Bioorg. Med. Chem. Lett. 2008, 18, 4118. b) Abe, H.; Kikuchi, S.; Hayakawa, K.; Iida, T.; Nagahashi, N.; Maeda, K.; Sakamoto, J.; Matsumoto, N.; Miura, T.; Matsumura, K.; Seki, N.; Inaba, T.; Kawasaki, H.; Yamaguchi, T.; Kakefuda, R.; Nanayama, T.; Kurachi, H.; Hori, Y.; Yoshida, T.; Kakegawa, J.; Watanabe, Y.; Gilmartin, A. G.; Richter, M. C.; Moss, K. G.; Laquerre, S. G. ACS Med. Chem. Lett. 2011, 2, 320.

${ }^{7}$ a) Lee-Ruff, E.; Mladenova, G. Chem. Rev. 2003, 103, 1449. b) Namyslo, J. C.; Kaufmann, D. E. Chem. Rev. 2003, 103, 1485. c) Sergeiko, A.; Poroikov, V. V.; Hanuš, L. O.; Dembitsky, V. M.; Open Med. Chem. J. 2008, 2, 26. d) Seiser, T.; Saget, T.; Tran, D. N.; Cramer, N. Angew. Chem. Int. Ed. 2011, 50, 7740. e) Poplata, S.; Tröster, A.; Zou, Y.-Q.; Bach, T. Chem. Rev. 2016, 116, 9748.

8 a) Chanthamath, S.; Iwasa, S. Acc. Chem. Res. 2016, 49, 2080. b) Pons, A.; Poisson, T.; Pannecoucke, X.; Charrette, A. B.; Jubault, P. Synthesis 2016, 48, 4060. c) Bos, M.; Poisson, T.; Pannecoucke, X.; Charrette, A. B. Chem. Eur. J. 2016, 23, 4950. d) Hoffmann, N. Chem. Rev. 2008, 108, 1052. e) Bach, T. Angew. Chem. Int. Ed. 2011, 50, 1000. f) Xu, Y.; Conner, M. L.; Brown, M. K. Angew. Chem. Int. Ed. 2015, 54, 11918.

${ }^{9}$ For selected examples of arylation of cyclopropyl organometallics, see: a) Molander, G. A.; Gormisky, P. E. J. Org. Chem. 2008, 73, 7481. b) Shu, C.; Sidhu, K.; Zhang, L.; Wang, X.-J.; Krishnamurthy, D.; Senanayake, C. H. J. Org. Chem. 2010, 75, 6677. c) Zhang, M.; Cui, X.; Chen, X.; Wang, L.; Li, J.; Wu, Y.; Hou, L.; Wu, Y. Tetrahedron 2012, 68, 900. d) Gülak, S.; Gieshoff, T. N.; von Wangelin, A. J. Adv. Synth. Catal. 2013, 355, 2197. e) Vila, C.; Giannerini, M.; Hornillos, V.; Fañanas-Mastral, M.; Feringa, B. L. Chem. Sci. 2014, 5, 1361. f) Grezler, S. N.; Halvorsen, G. T.; Voight, E. A. Org. Lett. 2017, 19, 2490.

${ }^{10}$ For selected examples of arylation of cyclobutyl organometallics, see: ref. 9a and a) Li, C.; Xiao, G.; Zhao, Q.; Liu, H.; Wang, T.; Tang, W. Org. Chem. Front. 2014, 1, 225. b) Li, L.; Zhao, S.; Joshi-Pangu, A.; Diane, M.; Biscoe, M. R. J. Am. Chem. Soc. 2014, 136, 14027. c) Primer, D. N.; Karakaya, I.; Tellis, J. C.; Molander, G. A. J. Am. Chem. Soc. 2015, 137, 2195.

${ }^{11}$ a) Moriconi, A.; Cesta, M. C.; Cervellera, M. N.; Aramini, A.; Coniglio, S.; Colagioia, S.; Beccari, A. R.; Bizzarri, C.; Cavicchia, M. R.; Locati, M.; Galliera, E.; Di Benedetto, P.; Vigilante, P.; Bertini, R.; Allegretti, M. J. Med. Chem. 2007, 50, 3984. b) Vetica, F.; Pelosi, A.; Gambacorta, A.; Loreto, M. A.; Miceli, M.; Gasperi, T. Eur. J. Org. Chem. 2014, 6625.

12 a) Chen, H.; Deng, M.-Z. J. Chem. Soc., Perkin Trans. 1 2000, 1609. b) Chen, H.; Deng, M.-Z. J. Org. Chem. 2000, 65, 4444. c) Colombel, V.; Rombouts, F.; Oehlrich, D.; Molander, G. A. J. Org. Chem. 2012, 77, 2966.

13 de Lang, R.-J.; Brandsma, L. Synth. Commun. 1998, 28, 225.

${ }^{14}$ a) Ren, P.; Stern, L.-A.; Hu, X. Angew. Chem. Int. Ed. 2012, 51, 9110. b) Suzuki, T.; Ozasa, H.; Itoh, Y.; Zhan, P.; Sawada, H.; Mino, K.; Walport, L.; Ohkubo, R.; Kawamura, A.; Yonezawa, M.; Tsukada, Y.; Tumber, A.; Nakagawa, H.; Hasegawa, M.; Sasaki, R.; Mizukami, T.; Schofield, C. J.; 
Miyata, N. J. Med. Chem. 2013, 56, 7222 .c) Lu, J.-Y.; Du, Y.; Zhao, B.; Lu, J. Tetrahedron 2016, 72, 161 d) Wey, H. G.; Betz, P.; Butenschoen, H. Chem. Ber. 1991, 124, 465.

${ }^{15}$ Jia, Z.; Liu, Q.; Peng, X.-S.; Wong, H. N. C. Nat. Comm. 2016, 7, 10614.

${ }^{16}$ For a deborylative alkylation, see: Hong, K.; Liu, X.; Morken, J. P. J. Am. Chem. Soc. 2014, 136, 10581.

${ }^{17}$ Zultanski, S. L.; Fu, G. C. J. Am. Chem. Soc. $2011,133,15362$.

${ }^{18}$ For selected reviews, see : a) Cahiez, G.; Moyeux, A. Chem. Rev. 2010, 110, 1435 1435. b) Gosmini, C.; Bégouin, J.-M.; Moncomble, A. Chem. Commun. 2008, 3221.

${ }^{19}$ For selected examples of Co-catalyzed cross-coupling involving alkyl halides: a) Ohmiya, H.; Yorimitsu, H.; Oshima, K. J. Am. Chem. Soc. 2006, 128, 1886. b) Ohmiya, H.; Yorimitsu, H.; Oshima, K. Org. Lett. 2006, 8, 3093. c) Cahiez, G.; Chaboche, C.; Duplais, C.; Giulliani, A.; Moyeux, A. Adv. Synth. Catal. 2008, 350, 1484. d) Cahiez, G.; Chaboche, C.; Duplais, C.; Moyeux, A. Org. Lett. 2009, 11, 277. e) Iwasaki, T.; Takagawa, H.; Singh, S. P.; Kuniyasu, H.; Kambe, N. J. Am. Chem. Soc. 2013, 135, 9604. f) Hammann, J.; Steib, A. K.; Knochel, P. Org. Lett. 2014, 16, 6500. g) Iwasaki, T.; Yamashita, K.; Kuniyasu, H.; Kambe, N. Org. Lett. 2017, 19, 3691.

${ }^{20}$ a) Guérinot, A.; Reymond, S.; Cossy, J. Angew. Chem. Int. Ed. 2007, 46, 6521. b) Nicolas, L.; Angibaud, P.; Stansfield, I.; Bonnet, P.; Meerpoel, L.; Reymond, S.; Cossy, J. Angew. Chem. Int. Ed. 2012, 51, 11101. c) Barré, B.; Gonnard, L.; Campagne, R.; Reymond, S.; Marin, J.; Ciapetti, P.; Brellier, M.; Guérinot, A.; Cossy, J. Org. Lett. 2014, 16, 6160. d) Gonnard, L.; Guérinot, A.; Cossy, J. Chem. Eur. J. 2015, 21, 12797. e) Barde, E.; Guérinot, A.; Cossy, J. Org. Lett. 2017, 19, 6068.

${ }^{21}$ For the whole optimization study, see the Supporting Information.

${ }^{22}$ Compounds 2.1, 3.1, 4.1 and $\mathbf{5 . 1}$ could not be separated by flash chromatography on silica gel. The indicated yields were calculated from the ${ }^{1} \mathrm{H}$ NMR spectrum of the mixture $\mathbf{2 - 5}$ obtained after purification.

${ }^{23}$ Primary bromides revealed less reactive than iodides under the optimized conditions and stirring the reaction at $\mathrm{rt}$ for $1 \mathrm{~h}$ was necessary to ensure full conversion of the starting material, which led to the coupling product in moderate yield (45\%).

${ }^{24}$ When the reaction was conducted on $1 \mathrm{mmol}$ of 1.1, the coupling product was isolated with a good yield of $87 \%$ and no trace of by-products was detected. The reaction was also carried out on $3.6 \mathrm{mmol}$ of $\mathbf{1 . 1}(1 \mathrm{~g})$ and the coupling product was obtained with a yield of $82 \%$ contaminated by $2 \%$ of dehalogenated product, see the Supporting Information for details. The rate of addition of the Grignard reagent can be increased to 26 $\mathrm{mmol} / \mathrm{h}$, providing the coupling product in $80 \%$ yield contaminated by $9 \%$ of side-products.

25 In some cases, the coupling products were isolated together with a small amount of elimination and/or dehalogenation products $(<7 \%)$ that could not be separated by flash chromatography, see Supporting Information for details.

${ }^{26}$ The tertiary alcohol resulting from a bis-addition of the Grignard reagent on the ester was also isolated ( $5 \%$ yield). When a catalytic amount of LiI $(7 \mathrm{~mol} \%)$ was added to the catalytic system $\left[\mathrm{Co}(\mathrm{acac})_{2}(3.5 \mathrm{~mol} \%)\right.$, TMEDA (3.5 mol \%)] an improved yield (71\%) in $\mathbf{2 . 7}$ was obtained. The effect of LiI is not fully understood.

${ }^{27}$ The coupling product $\mathbf{2 . 8}$ was isolated together with dehalogenation and elimination products (38\%).

${ }^{28}$ For other examples of radical intermediate formation during Cocatalyzed cross-coupling, see : a) Wakabayashi, K.; Yorimitsu, H.; Oshima, K. J. Am. Chem. Soc. 2001, 123, 5374. b) Ohmiya, H.; Tsuji, T.; Yorimitsu, H.; Oshima, K. Chem. Eur. J. 2004, 10, 5640. c) Affo, W.; Ohmiya, H.; Fujioka, T.; Ikeda, Y.; Nakamura, T.; Yorimitsu, H.; Oshima, K.; Imamura, Y.; Mizuta, T.; Miyoshi, K. J. Am. Chem. Soc. 2006, 128, 8068. d) Ohmiya, H.; Wakabayashi, K.; Yorimitsu, H.; Oshima, K. Tetrahedron 2006, 62, 2207. e) Someya, H.; Ohmiya, H.; Yorimitsu, H.; Oshima, K. Org. Lett. 2007, 9, 1565. f) Someya, H.; Ohmiya, H.; Oshima, K. Tetrahedron 2007, 63, 8609. and ref 19.

${ }^{29}$ The cross-coupling between iodide $\mathbf{1 . 1}$ and cyclopropylmagnesium bromide was performed under the optimized conditions in the presence of 1 equiv of $(E)$-stilbene as a radical scavenger. The addition of $(E)$-stilbene showed no significant effect on the outcome of the reaction $(71 \%$ yield in 2.1) and no adduct resulting from a radical attack on the activated olefin could be detected. This result could be explained by kinetic reasons, the recombination of the radical with the metal complex being faster than the intermolecular reaction.

${ }^{30}$ For examples of Co-catalyzed alkenylation of alkyl halides, see: 19a, $19 \mathrm{~b}$.

${ }^{31}$ Cross-coupling product $\mathbf{6 . 2}$ was isolated together with $13 \%$ of dehalogenation and elimination products. 